\title{
Factors affecting Faculty Job Satisfaction and Leader's Influence in a Pakistani Public University
}

\author{
Dr. MUHAMMAD AMIN \\ Assistant Professor in Education, Department of STEM Education, \\ Division of Education, University of Education, Lahore. \\ Ed.D (Doctor of Education), University of Leicester, England, UK. \\ Email: amin@ue.edu.pk \\ Tel: 0333-7075061 \\ Dr. FARRUKH MUNIR \\ Assistant Professor in Education \\ Institute of Education and Research, University of the Punjab, Lahore. \\ Ph.D. Education, University of Education, Lahore. \\ Email: farrukhier@yahoo.com
}

\section{Ms. SAMRA BASHIR}

Lecturer in Education, Department of STEM Education,

Division of Education, University of Education, Lahore.

Email: samrabashir@ue.edu.pk

\begin{abstract}
This research focuses to explore the factors affecting the faculty members' job satisfaction and the influence that the campus/division head has upon these factors in a Pakistani public university. To conduct the research qualitative method has been used. The selected public university has 13 campuses/divisions. Twenty-six faculty members, two from each campus/division, who had at least three years of working experience with the present head (leader) in the current campus/division have been interviewed. The semistructured type of qualitative interview was adopted to generate comprehensive data. 'Content analysis' was employed to analyze the data. A range of factors was revealed from the data that were affecting the job satisfaction of faculty members. Six main themes have been developed and the identified factors are collated under these themes. The major themes include institutional factors, leader-related factors, colleague-related factors, student-related factors, personal factors, and job-related factors. The faculty job satisfaction factors related to the institution, leader, and job are influenced by the leader, whereas factors related to colleagues, students, and faculty themselves are not influenced by the leader. Some suggestions for the practice, policy, and future researchers are presented.
\end{abstract}

Keywords: Job Satisfaction, Leader's Influence, Public University Context.

\section{Introduction}

The study aims to investigate the faculty job satisfaction factors and the influence that their leaders have upon these factors. Job satisfaction has been defined differently by many researchers (Al Khajeh, 2018; Nidadhavolu, 2018; Armstrong, 2006; Evans, 2000), and it has no agreed definition (Worrell, 2004; Zembylas \& Papanastasiou, 2006) because of its "elusive" (Castillo \& Cano, 2004, p. 65) and "even mythical" nature (Karimi, 2008, p. 3). In general, job satisfaction is defined as the extent to which a job meets the needs of a worker and provides him/her with pleasure (Nidadhavolu, 2018). Some researchers 
perceive it as the emotional satisfaction which results from an employee's job experience (Lien, 2017). This emotional satisfaction is achieved when an employee's job offers something that $s /$ he feels is worthwhile (Nguni, Sleegers, \& Denessen, 2006; Lofquist \& Dawis, 1991). Whereas, others consider job satisfaction to be the attitude or feeling that an employee has towards his/her job (Evans, 1999; Roberts, 2001). In the current research context, job satisfaction is considered as the faculty members' positive and favorable attitudes and feelings that they have for their jobs (Armstrong, 2006). A leader's influence on the faculty's job satisfaction is considered so critical that sometimes faculty members quit or retain in their job because of a leader's behavior (Amin, 2012). However, being university faculty members for the last eight years, researchers maintain that sometimes faculty members give sweeping statements and hold leaders as solely responsible for their job dissatisfaction although factors that cause their job dissatisfaction are not linked with the leader. Further, as per the knowledge of researchers, no study at the university level addressed these questions. The researchers usually use tools to investigate faculty job satisfaction that are developed in the Western context. Researchers believe that the causes of job satisfaction and dissatisfaction vary across individuals, organizational context, and societal settings. The study will provide a base to develop the job satisfaction tool keeping in view the factors identified in the local settings. Therefore the study focusses to identify which factors affect the faculty job satisfaction in the Pakistani university context. The study is also focused to differentiate which of these faculty job satisfaction factors are influenced and which are not influenced by the leader. Since the study is exploratory in nature therefore no previous theory is presented as a base of this study.

\section{Literature Review}

There are several studies throughout the world from different educational settings, such as schools and universities that have investigated the factors that affect teachers/faculty members' job satisfaction (Fessehatsion and Bahta, 2016; Al-Omari, 2008; Cerit, 2009; Nguni et al., 2006; Seseer, 2007). The studies from different cultural contexts and organizational settings found some different factors which significantly influenced the teachers'faculty members' job satisfaction. This highlights the significance of culture and context in the study of job satisfaction. Some job satisfaction factors are considered more critical than others in different societal contexts and organizational settings. Giacometti (2005), for example, in the American school setting (an individualistic societal context), highlights that emotional factors, compensation and benefits, cultural shock, induction, mentoring, professional development, administrative support, a positive environment within the institution, and student-related issues are the significant factors that affect teachers' job satisfaction. The researchers from more individualistic societies, such as Ingersoll (2001), Luekens, Lyter, and Fox (2004), Ambrose, Huston, and Norman (2005) and Castillo and Cano (2004) from the American school and university context, and Oshagbemi (1997) from the British context support these findings.

These are in contrast to Sharma and Jyoti (2009) from a collective societal context (in Jammu and Kashmir at the university level). They explored the factors which affected faculty members' job satisfaction significantly. They found that job-related factors, such as a sense of achievement, creativity, autonomy within the job, and being appropriate and ideal for the job, and other factors, for example mentoring, an opportunity for higher education, professional development, appreciation and recognition, compensation, issues related with students and colleagues, working environment, and promotion affected faculty members' job satisfaction significantly. Other researchers from more collective societies, such as Zembylas and Papanastasiou (2006) from the Cypriot school context, Karimi (2008) from the Iranian university context, Dusitsutirat (2009) from the Thai university context, Sargent and Hannum (2005) from the Chinese school context, Toker (2011) from the Turkish university context and Alam, Talha, Sivanand, and Ahsan (2005) and Tasnim (2006) from the Bangladeshi school context support these findings.

The study responds to Bogler's (2001, p. 677) call regarding job satisfaction that "future studies should investigate the concept of teachers' job satisfaction by distinguishing its constituents". Santhapparaj and Alam (2005, p. 72) highlight that "there have been several job satisfaction studies, [however] very few of them have been focused on the job satisfaction of the university teachers, in general" (see also Toker, 2011, 
p. 156; Tasnim, 2006). They further point out that "most of the studies have been reported before 1981 [and] ...most of these relevant studies were focused on UK universities... [and] academic staffs in... the US" (Santhapparaj \& Alam, 2005, p. 72, see also Zembylas \& Papanastasiou, 2006, p. 229; Alam et al., 2005, pp. 88-89), and "literature on ...[and] research ...[regarding] teacher job satisfaction in developing countries is relatively limited” (Zembylas \& Papanastasiou, 2006, p. 229). Whatever limited research has been carried out on this concept in developing countries "was based on a set of theoretical assumptions that had been developed from findings in developed countries" (Garrett, 1999, as cited in Zembylas \& Papanastasiou, 2006, p. 232).

Moreover, the reason behind investigating job satisfaction factors in the present study is that these factors differ in different cultural contexts (Toker, 2011; Giacometti, 2005; Oshagbemi, 1997; Tasnim, 2006; Karimi, 2008; Dusitsutirat, 2009), because of "the social context of the teachers, the teachers' attitudes and their working conditions [which] are intimately related in a very complex manner" (Garrett, 1999, p. 2) and differ in distinct cultural contexts and settings. For example, in some contexts such as UK, USA, New Zealand, and Australia teachers join the teaching profession because of intrinsic factors (Dinham \& Scott, 2000; Evans, 2001; Scott \& Dinham, 2003), whereas teachers in Cyprus join this profession because of extrinsic factors (Zembylas \& Papanastasiou, 2004). Intrinsic factors come from within the individual such as job-related factors, whereas extrinsic factors are related to the external world of an employee such as factors linked with the working environment (Al-Omari, 2008).

Furthermore, the faculty members' job satisfaction in the higher education context is critical (Toker, 2011; Küskü, 2003) because "higher education institutions are labor-intensive and their budgets are predominantly devoted to personnel and their effectiveness is largely dependent on their staff" (Toker, 2011, p. 156, see also Capelleras, 2005). Therefore, job satisfaction "needs to be researched further in academic work-life" (Toker, 2011, p. 166). However, there is a paucity of research in this area in Pakistan, as there is not a single study (up to the researchers' knowledge) that explores the factors affecting university faculty job satisfaction in Pakistan; and previous research evidenced that no study has been done to investigate which faculty job satisfaction elements are influenced/not influenced by the leader. This paper is, therefore, aimed to investigate the following research question:

\section{Research Question}

What are the faculty job satisfaction elements and which of these elements might and might not be influenced by the leader in the Pakistani public university context as perceived by the faculty?

\section{Methodology}

The qualitative approach has been adopted to conduct the study; therefore it falls in the interpretive paradigm philosophically. The study aims to investigate the perception of the faculty members regarding factors that affect their job satisfaction and the influence that their leaders have upon these factors. The study is exploratory in nature. To collect in-depth qualitative data a semi-structured interview protocol has been used. From a total of 13 units (campuses/divisions) of a chosen public university, 26 faculty members were interviewed - two faculty members selected randomly from each site. However, within random selection quota sampling was used to select 13 male and 13 female faculty members.

The twenty-six faculty members had a minimum three years of working experience with the current head in the present campus/division and were willing for the interview. The data has been analyzed through 'content analysis' (Cohen, Manion and Morrison, 2017). Content analysis aligns better with the purpose of the inquiry as the data generated through a semi-structured interview is under pre-defined broader themes. The proposed frame has been useful for exploring the similarities and differences across the participants' responses, to organize, conclude and report the main content and message of the data (Cohen, et al., 2017). 


\section{Data Presentation and Findings}

This section presents the data and the related research findings derived from it. The participants were first asked to identify significant elements of their job satisfaction before inquiries were made into which significant elements of their job satisfaction were influenced by the leader, and which significant elements of their job satisfaction were not influenced by the leader. The data were collated under two headings: significant elements of faculty job satisfaction and faculty job satisfaction elements influenced/not influenced by the leader.

\section{Significant Elements of Faculty Job Satisfaction}

The data generated revealed an array of significant elements affecting faculty job satisfaction. These factors are grouped under the following six themes: institutional factors, leader-related factors, colleague-related factors, student-related factors, personal factors, and job-related factors, as presented in the figure on the next page. Quotations from participants' interviews presented as evidence in the next section are made very brief to meet the paper's word limit.

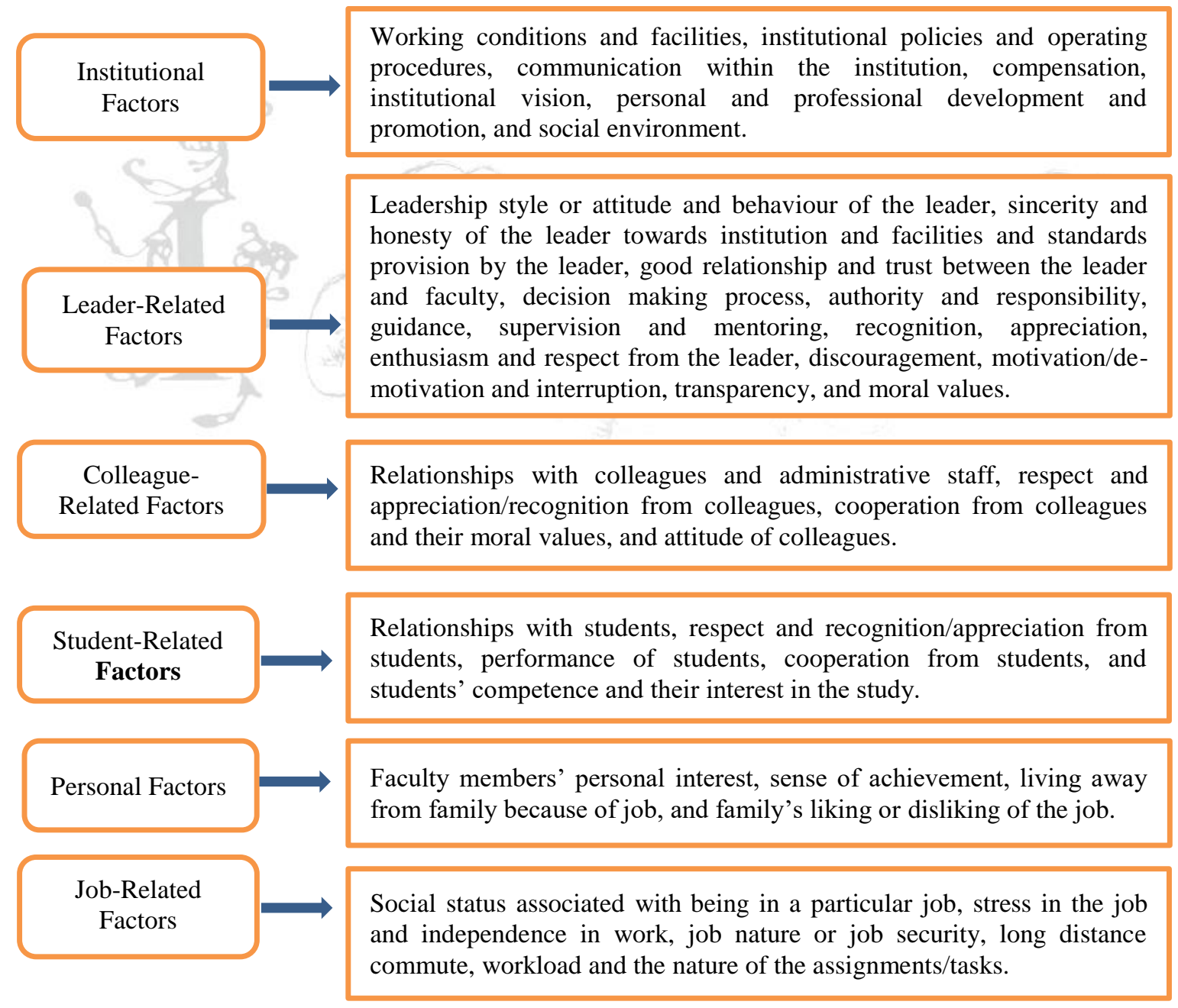

Fig 1: Summary of Factors which Influence the Faculty Job Satisfaction Significantly 
Institutional Factors: The data evidenced that all twenty-six of the respondents considered the institutional factors as significant in contributing to their satisfaction within their jobs. Participants maintained that:

Good working conditions...(Respondent $(\mathrm{R}) 14,15 \& 17) \ldots$, provision of the facilities for research...(R3\&24) [and] ...for job [execution] (R11\&13), institutional policies...(R4,7,\&21), clear and proper communication...(R7,8\&16), reasonable salary...(R1,14\&9), future plan [vision] of the institution with reference to growth...(R2,19\&25), conducive and friendly social environment...(R3,10\&23), and availability of opportunities for carrier growth and for higher education [are] significant factor[s] for faculty job satisfaction (R26).

Leader-Related Factors: All the twenty-six respondents claimed that the leader, the leader's leadership style, and other factors related to the leader were more important than any other factor for the faculty members' job satisfaction. The participants highlighted a number of factors as is evidenced below:

The most important and crucial factor which significantly might affect job satisfaction is leadership style or attitude and behaviour of the leader...(R1) [including] leader's call to participate in the decision making process...(R8), when he/she gives me authority and place confidence upon me(R14)...the way he/she guides, supervises and develops me personally and professionally (R18), ...sincerity and honesty of the leader towards [the] institution (R2), ...recognition and appreciation...(R13\&24), enthusiasm and respect from leader...(R7,11,20\&22), trustworthy relationship between the leader and faculty,[and] fair treatment...(R5), [and] high moral values of the leader... (R5,10,12\&23).

However, no respect, discouragement from the leader, undue interruption/hurdles from the leader [while] (R6) ...doing any good job, de-motivation from the leader, unfair treatment and weak values reduce faculty satisfaction within the job (R15).

Colleague-Related Factors: Colleague-related factors are also considered critical by almost all the participants, who maintained that:

Good relationships with colleagues...(R2,12\&21) [and] administration... (R10,15\&17), appreciation and respect from faculty members...(R1,11\&26), moral values of my colleagues [and their] cooperation... (R7\&19) [and] good attitude of other faculty members towards me increase my job satisfaction (R9), ...[but] bad relationships with colleagues...(R6,13\&24), de-motivation and no appreciation from colleagues [and] problems created by faculty members dissatisfies me from my job (R14).

Student-Related Factors: The data highlighted that many respondents pointed out various student-related factors as important to satisfying faculty members within their jobs - as is evidenced in participants' responses below:

Relationship[s] with the students...(R2,3,16\&18,), respect and recognition/appreciation... (R7,13\&23) [and]cooperation from the students (R9,22\&25), competent students and their interest in the study (R10\&20), [and] performance and achievements of the students both in curricular and extracurricular activities lead towards job satisfaction (R 12).

Personal Factors: The majority of the participants indicated that the faculty members' issues were also significant elements of their job satisfaction - the below responses are presented as an example:

Profession of interest...(R5,9,14\&21), sense of achievement... (R4,6\&17), living away from family due to job... (R7\&8) especially with reference to the female faculty members... (R15), [and] family's liking or disliking of the job matters a lot for job satisfaction (R19). 
Job-Related Factors: All the participants indicated many job-related factors that might influence job satisfaction positively or negatively: As respondents maintained that:

Social respect from the society... (R14\&15), permanent or contractual nature of [the] job...(R5\&13), stress in the job...(R2), independence in my job...(R15), long distance to travel to reach [on]the job...(R12\&18), workload...(R15\&20), [and] nature of assignments/tasks...may become a source of [job] satisfaction/dissatisfaction (R24).

\section{Faculty Job Satisfaction Elements influenced/not influenced by the Leader}

The respondents pointed out several factors which in their view significantly affected faculty job satisfaction either positively or negatively and were influenced by the leader. The majority of these factors were related to the leader as an individual, while some of these were related to the institution and the job. The factors which positively affected job satisfaction included leadership style, sincerity and honesty of the leader towards the institution and his/her plan/s regarding the institution, trust, and relationship between the leader and faculty members, faculty's participation in the decision-making process, confidence placed by the leader upon faculty members through sharing authority, responsibility and providing autonomy in job execution, guidance, supervision and mentoring provided by the leader, appreciation, motivation, and respect given by the leader, a conducive working environment and facilities provision, fair distribution of workload and assignment of work according to the interest of the faculty members, fair compensation of rewards according to the workload, implementation of institutional policies, enthusiastic leadership, communication within the institution, and the moral values of the leader and maintenance of these values in the faculty. The factors which negatively affected job satisfaction included discouragement and demotivation from the leader, hurdles and undue interruption by the leader, and no respect from the leader.

Darling-Hammond and Sclan (1996) maintain that a 'conducive working environment' is directly influenced by the leader. Sargent and Hannum (2005, p. 183), similar to the present study, argue that "...leadership and supervision affect a range of factors in the school environment, including the overall organizational climate of the school". Concerning other leader-related factors, no empirical evidence has been found in previous research that these elements are significantly influenced by the leader. However, associating all these factors to leaders in the current research context can be linked to the organizational structure and culture in the context of this study because of the leader's legitimate power and responsibilities linked to their position. In the context of the present study the leader (campus principal/divisional director) works under a vice-chancellor and is responsible for the entire administrative, academic, and research affairs of the subordinate faculty and campus/division (Provincial Assembly Punjab, 2004). Therefore, the leader's influence emerges as significant concerning faculty job satisfaction.

The data unveiled some factors which affected the faculty job satisfaction significantly, but were not influenced by the leader. Such factors were often related to the faculty members themselves, their families, colleagues and students, while several were linked with the job, society and the institution. These factors included interpersonal relationships with other faculty members and students, respect and recognition/appreciation given to a faculty member by other faculty members and students, living away from family because of the job, permanent or contractual nature of the job, a long distance commute, social respect or status a faculty member received from society for being in a particular job, compensation including all kinds of fringe benefits, allowances and annual increment, institutional policies, personal interest of the faculty member within the job, family's liking or disliking of the job, faculty member's sense of achievement, and performance of the students.

\section{Discussion}

The findings revealed in the above section are compared and contrasted with the previous research findings. This discussion has been supported by various research studies drawn from diverse cultural 
contexts and educational settings encompassing different educational levels (school, college, and university); however, a point to be noted is that almost all of these studies have been carried out quantitatively. Moreover, as the researchers are also working at the university level for the last eight years in the same context, the current research findings are also discussed with reference to the local cultural and organizational setting.

There are many studies, conducted in various cultural contexts and at different educational levels (school, college, and university), that found most of the institutional factors significant for teacher/faculty job satisfaction (Lien, 2017; Alam et al., 2005; Castillo \& Cano, 2004; Heller, Clay, \& Perkins, 1993; Karimi, 2008; Meyer \& Allen, 1997; Nestor \& Leary, 2000; Schneider, 2003; Stumpf, 2003; Toker, 2011). For example, Lien (2017) and Santhapparaj and Alam (2005, p.72) pointed out that "pay, promotion, working condition and support of research have a significant effect on job satisfaction", while a lack of proper promotion and conducive policies cause job dissatisfaction (Fessehatsion and Bahta, 2016; Oshagbemi, 1997, p.357; Tasnim, 2006; Sharma \& Jyoti, 2009; Zembylas \& Papanastasiou, 2006; Sargent \& Hannum, 2005). Lien (2017) and Santhapparaj and Alam (2005, p. 72) also show that unreasonable "fringe benefits and support of teaching have [a] negative effect" on faculty job satisfaction. Regarding compensation, similar to the current study, Dusitsutirat $(2009$, p. 1097) argues that "the university administrators have to be fair on payment for teacher's teaching hour... [and] if the university delivers good welfare, teachers will satisfy with [their] current job status". Personal and professional development and the social environment are also highlighted as important factors in faculty job satisfaction (Lien, 2017; Fessehatsion and Bahta, 2016; Bogler, 2001; Giacometti, 2005; Hugick \& Leonard, 1991; Luekens et al., 2004). 'Institutional vision', on the other hand, is a unique significant element of faculty job satisfaction in the Pakistani context, which has not been shown in the previous research referred to in this study.

Many leader-related factors have been pointed out as significant elements of teacher/faculty job satisfaction in past studies (Al Khajeh, 2018 Bogler, 2001; Castillo \& Cano, 2004; Grosso, 2008; Karen, 1999; Karimi, 2008; Leary, Sullivan, \& Ray, 1999; Seseer, 2007; Toker, 2011). For example, Lien (2017) and Sharma and Jyoti (2009, p. 64) highlight that "good administration, appreciating the subordinates, [and] impartiality ...have added to the satisfaction of the university teachers. It indicates that positive attributes and behavior of the leader heightens the degree of satisfaction of his subordinates" (see also Oshagbemi, 1997). Tasnim (2006) points out that the relationship with the leader and their leadership style are important factors for teacher job satisfaction. Ingersoll and Kralik (2004) maintain that mentoring from the leader is a significant factor for their teachers' job satisfaction. However, some factors such as sincerity and honesty of the leader towards the institution, trust between the leader and the faculty, motivation from the leader, facilitation and standards provision, interruption caused or hurdles created by the leader, discouragement from the leader, transparency and the moral values of the leader, have not been highlighted as significant factors in faculty job satisfaction/dissatisfaction in the previous research. These factors have been found as new elements that are significant for faculty job satisfaction/dissatisfaction in this research context.

Moreover, the findings from previous studies affirm the significance of the relationship between colleagues as an important factor for teacher/faculty job satisfaction (Fessehatsion and Bahta, 2016; Alam et al., 2005; Castillo \& Cano, 2004; Dinham, 1995; Heller et al., 1993; Karimi, 2008; Nguni et al., 2006; Rahim \& Afza, 1993; Tasnim, 2006; Worrell, 2004). Ramakrishnaiah (1998) points out that those college academics who expressed job satisfaction had good relationships with their colleagues. Manger and Eikeland (1990) highlight bad relationships between faculty members and their colleagues as the main factor in the intention to leave the university. Sharma and Jyoti (2009) and Oshagbemi (1997) show that university faculty members' satisfaction within the job might be influenced by their colleagues' behavior, which is somewhat similar to the 'attitude of colleagues' factor highlighted in the present study. Zembylas and Papanastasiou (2006) report that cooperation from colleagues is the main source of teacher job satisfaction. The current study, however, reveals some new factors related to the colleagues that have a significant effect on faculty 
job satisfaction; these include, respect and appreciation/recognition from colleagues, and the moral values of the colleagues.

Further, Dinham (1995), Tasnim (2006), and Shann (1998) highlighted the relationship with students, and Oshagbemi (1997) found respect from students as significant factors for faculty job satisfaction. Plihal (1982), Heller, Clay, and Perkins (1992) and Taylor and Tashakkori (1995) pointed out that student achievement/good performance is important for faculty job satisfaction, and Zembylas and Papanastasiou (2006) identified that students' failure is a source of job dissatisfaction for the faculty members. However, the other student-related factors, such as recognition/appreciation from students, cooperation from students, and students' competence and their interest in the study, were identified as significant for faculty job satisfaction and are new findings specific to this context.

Furthermore, the prior studies which explored the personal aspect of teachers/faculty job satisfaction examined the 'sense of achievement' factor, and the findings of the present study regarding this factor are consistent with the previous studies (Al-Omari, 2008; Bogler, 2001; Castillo \& Cano, 2004; Cerit, 2009; Karimi, 2008; Sharma \& Jyoti, 2009). For example, Tasnim (2006, p. 87) argued that "the teachers are the architect of nation-building. They are building the future of the nation. This belief is [a] great achievement of the teachers. Such achievement is [a source of] job satisfaction to them". However, factors such as personal interest in the job, living away from family because of the job, and family's liking or disliking of the job, have not been identified by earlier studies.

Finally, the majority of the findings in the present study regarding job-related factors are consistent with many previous studies (Al-Omari, 2008; Castillo \& Cano, 2004; Nguni et al., 2006; Oshagbemi, 1997; Worrell, 2004). For example, Bogler (2001, p. 676) found that social status and independence in work "contribute the most to job satisfaction" (see also Toker, 2011, p. 164; Tasnim, 2006; Giacometti, 2005). Regarding the nature of work, Dusitsutirat (2009, p. 1097) maintains that "work characteristic was a key factor which motivates or encourages staff to have job satisfaction and work more effectively" (see also Karimi, 2008, p. 9). Sharma and Jyoti (2009, p. 63) argue that "the element of job security [that] keeps the teachers intact with their present jobs ... [and] proper workload... are some of the elements of [the] job that account for maximum job satisfaction of university academicians" (see also Tasnim, 2006; Luekens et al., 2004). Zembylas and Papanastasiou (2006) highlight that a lack of respect, status, and recognition from society and a lack of autonomy lead towards job dissatisfaction. Contrary to the findings of the present study, Sargent and Hannum (2005, p. 202) found that "teachers with greater workloads tend to have higher levels of [job] satisfaction"; however, Luekens et al. (2004) support the findings of the current study in this regard. Yet, some factors such as stress in the job and a long commute have been examined in relatively few studies (Hugick \& Leonard, 1991). Giacometti (2005) and Blackburn, Horowitz, Edington, and Klos (1986) establish that job-related stress, similar to the present study, has a negative effect upon teachers/faculty job satisfaction.

The findings support the "view that the job of workers alone may not fully explain their job satisfaction... [and] contrary to the two-factor theory, there are situational occurrences about a job which are often important in determining overall job satisfaction or dissatisfaction" (Oshagbemi, 1997, p. 359). Therefore, the findings support the situational theory of job satisfaction which argues that any factor can cause either job satisfaction or dissatisfaction.

\section{Conclusion}

The findings revealed several significant elements of faculty job satisfaction, as presented in the fourth section. Most of the faculty members' personal, family-related, colleague-related, job-related, and studentrelated job satisfaction factors are influenced by cultural values and norms, patterns of behavior, and the collective nature of the Pakistani society. The majority of the faculty job satisfaction factors linked with the 
institution and leader are influenced by the higher education system of Pakistan and the organizational culture and context of the specific university under study.

In essence, "multiple factors including faith, culture, ethnicity, dominant values, [gender] and relationships influence patterns of work, attitude to work, attitude to professional development, response to leadership role and other practices on professional sites" (Shah, 2009, p. 10), which have significant effects on faculty job satisfaction. As these factors vary across societies and nations, faculty members in different societal contexts have highlighted different job satisfaction factors (Zembylas \& Papanastasiou, 2006; Castillo \& Cano, 2004; Karimi, 2008; Oshagbemi, 1997). Therefore, several faculty job satisfaction factors revealed in this study, as highlighted previously are unique to this research context. The majority of the faculty job satisfaction factors are influenced by leaders because of the leaders' powers, which they draw from culture, religion, and societal sources. So, the leader as an individual, their leadership style, and other factors related to the leader are critical if they want faculty to keep satisfied within their job. In conclusion, the above debate highlights the importance of culture and context in defining and taking initiatives to satisfy faculty members in jobs.

The findings of the study suggest that leaders need to exercise the appropriate leadership behavior to keep the faculty members satisfied in their job because it is the satisfied faculty member who mainly contributes to institutional excellence. University management and Higher Education Commission may inform the policy, keeping in view the findings of the current study, to keep the faculty members satisfied. Future researchers are suggested to conduct more such studies in a public and private university context to explore the local factors that influence the faculty job satisfaction and the leader's role in it. This research may be extended to the college and school sectors as well.

\section{References}

Al Khajeh, E. H. (2018). Impact of Leadership Styles on Job Satisfaction. Journal of Human Resources Management Research, Article ID 939089, DOI: 10.5171/2018.939089.

Alam, S. S., Talha, M., Sivanand, C. N., \& Ahsan, M. N. (2005). Job satisfaction of university woman teachers in Bangladesh. Journal of Social Sciences, 1(2), 88-91.

Al-Omari, A. (2008). The relationship between leadership styles of Hashemite university department chairs and job satisfaction as reported by department faculty members. University of Sharjah Journal for Humanities \& Social Sciences, 5(2), 101-124.

Ambrose, S., Huston, T., \& Norman, M. (2005). A qualitative method for assessing faculty satisfaction. Research in Higher Education, 46(7), 803-830.

Amin, M. (2012). The relationship of principals/directors' leadership styles, as perceived by the faculty, to the job satisfaction of the faculty members in a public university of Punjab, Pakistan (Doctoral thesis, University of Leicester, Leicester, England). Retrieved from https://leicester.figshare.com/articles/The_Relationship_of_Principals_Directors_Leadership_Styles_as _Perceived_by_the_Faculty_to_the_Job_Satisfaction_of_the_Faculty_Members_in_a_Public_Universi ty_of_Punjab_Pakistan/10107758/1

Armstrong, M. (2006). A handbook of human resource management practice. London, England: Kogan Page.

Bass, B. M., \& Avolio, B. J. (2004). Multifactor leadership questionnaire: manual and sampler set. Menlo Park, United States: Mind Garden, Inc.

Blackburn, R. T., Horowitz, S. M., Edington, D. W., \& Klos, D. M. (1986). University faculty and administrator responses to job strains. Research in Higher Education, 25(1), 31-41.

Bogler, R. (2001). The influence of leadership style on teacher job satisfaction. Educational Administration Quarterly, 37(5), 662-683.

Bryman, A. (2008). Social research methods. Oxford, England: Oxford University Press.

Capelleras, J. L. (2005). Attitudes of academic staff towards their job and organisation: an empirical assessment. Tertiary Education and Management, 11(2), 147-66. 
Castillo, J. X., \& Cano, J. (2004). Factors explaining job satisfaction among faculty. Journal of Agricultural Education, 45(3), 74-75.

Cerit, Y. (2009). The effects of servant leadership behaviours of school principals on teachers' job satisfaction. Educational Management Administration \& Leadership, 37(5), 600-623.

Cohen, L., Manion, L., \& Morrison, K. (2017). Research Methods in Education. $8^{\text {th }}$ Edition. London, United Kingdom: Taylor \& Francis Ltd.

Darling-Hammond, L., \& Sclan, E. M. (1996). Who teaches and why: dilemmas of building a profession for twenty-first century schools. In J. Sikula, T. J. Buttery \& E. Guyton (Eds.), Handbook of research on teacher education. New York, USA: Simon \& Schuster Macmillan.

Dinham, S. (1995). Time to focus on teacher satisfaction. Unicorn, 21(3), 64-75.

Dinham, S., \& Scott, C. (2000). Moving into the third, outer domain of teacher satisfaction. Journal of Educational Administration, 38(4), 379-396.

Dusitsutirat, A. (2009). Factors affecting on job satisfaction of teachers in Rajamangala University of Technology Krung - Thep. Paper presented at the International Conference on the Role of Universities in Hands-On Education, Chiang-Mai, Thailand.

Evans, L. (1999). Managing to motivate: a guide for school leaders. London, England: Cassell.

Evans, L. (2000). The effects of educational change on morale, job satisfaction and motivation. Journal of Educational Change, 1(2), 173-192.

Evans, L. (2001). Delving deeper into morale, job satisfaction and motivation among education professionals: re-examining the leadership dimension. Educational Management Administration \& Leadership, 29(3), 291-306.

Fessehatsion, P. W. and Bahta, D. T. (2016). Factors Affecting Academic Job Satisfaction in the Public Institutions of Higher Education, Eritrea. Research on Humanities and Social Sciences, 11(6), 1-6.

Garrett, R. M. (1999). Teacher job satisfaction in developing countries. Educational Research Supplemental Series $(G)$, ERIC Document Reproduction Service No. ED 459150.

Giacometti, K. S. M. (2005). Factors affecting job satisfaction and retention of beginning teachers, (Doctor dissertation). Retrieved from https://vtechworks.lib.vt.edu/handle/10919/29595

Grosso, F. A. (2008). Motivating faculty through transformational leadership: a study of the relationship between presidential leadership behaviours and faculty behaviours. Washington, USA: The Catholic University of America.

Heller, H. W., Clay, R., \& Perkins, C. (1992). Factors related to teacher job satisfaction and dissatisfaction. Journal of School Research and Information, 10(1), 20-24.

Heller, H. W., Clay, R., \& Perkins, C. (1993). The relationship between teacher job satisfaction and principal leadership style. Journal of School Leadership, 3(1), 74-86.

Hugick, L., \& Leonard, J. (1991). Job dissatisfaction grows: “moonlighting” on the rise'. Gallup Poll News Service, 56, 1-11.

Ingersoll, R. M. (2001). Teacher Turnover, teacher shortages, and the organization of schools. Seattle, Washington: Centre for the Study of Teaching and Policy.

Ingersoll, R., \& Kralik, J. (2004). The impact of mentoring on teacher retention: what the research says. Denver, Colorado: Education Commission of the States.

Karen, M. B. O. (1999). An examination of the perceived leadership styles of Kentucky public school principals as determinants of teacher job satisfaction (Doctoral dissertation, West Virginia University). Retrieved from http://www.google.com.pk/url?url=http://citeseerx.ist.psu.edu/viewdoc/download\%3Fdoi\%3D10.1.1.4 66.480\%26rep\%3Drep1\%26type\%3Dpdf\&rct=j\&frm=1\&q=\&esrc=s\&sa=U\&ved=0ahUKEwiPgpO_6 aXXAhUIn5QKHUHyDK0QFggiMAA\&usg=AOvVaw1AR2s_3LphtmBY-q19OTxF

Karimi, S. (2008). Factors affecting job satisfaction of faculty members of bu-ali sina university. Scientific \& Research Quarterly Journal of Mazandaran University, 23(6), 89-104.

Küskü, F. (2003). Employee satisfaction in higher education: the case of academic and administrative staff in turkey. Career Development International, 8(7), 347-356. 
Leary, P. A., Sullivan, M. E., \& Ray, D. A. (1999). The relationship of leadership styles of selected west virginia deans and department chairs to job satisfaction of departmental faculty members. National Forum of Educational Administration and Supervision, 16(4), 33-41.

Lien, P. T. (2017). Factors Affecting Lecturer Job Satisfaction: Case of Vietnam Universities. International Journal of Academic Research in Economics and Management Sciences, 2(6), 138-148.

Lofquist, L., \& Dawis, R. (1991). Essentials of person environment correspondence counselling. Minneapolis, Minnesota: University of Minnesota Press.

Luekens, M. T., Lyter, D. M., \& Fox, E. E. (2004). Teacher attrition and mobility, results from the teacher follow-up survey, 2000-01. Washington, USA: National Centre for Education Statistics. Retrieved from www.councilofcollaboratives.org/files/2004301.pdf

Manger, T., \& Eikeland, O. (1990). Factors predicting staff's intentions to leave the university. Higher Education, 19(3), 281-291.

Meyer, J. P., \& Allen, N. J. (1997). Commitment in the workplace: theory, research, and application. Thousand Oaks, California: Sage.

Nestor, P. I., \& Leary, P. (2000). The relationship between tenure and non-tenure track status of extension faculty and job satisfaction. Journal of Extension, 38(4). Retrieved from http://www.joe.org/joe/2000august/rb1.php

Nguni, S., Sleegers, P., \& Denessen, E. (2006). Transformational and transactional leadership effects on teachers' job satisfaction, organizational commitment, and organizational citizenship behavior in primary schools: the tanzanian case. School Effectiveness and School Improvement, 17(2), 145-177.

Nidadhavolu, A. (2018) Impact of Leadership Styles on Employee Job Satisfaction and Organizational Commitment - A Study in the Construction Sector in India. https://digitalcommons.wku.edu/theses/2090. Accessed on $10^{\text {th }}$ June 2020.

Oshagbemi, T. (1997). Job satisfaction and dissatisfaction in higher education. Education + Training, 39(9), 354-359.

Plihal, J. (1982, April). Types of intrinsic rewards of teaching and their relation to teacher characteristics and variables in the work setting. Paper presented at the Annual Meeting of the American Educational Research Association, New York.

Provincial Assembly Punjab (2004). Notification: The University of Education, Lahore. Lahore, Pakistan: Provincial Assembly of the Punjab, Pakistan.

Rahim, M. A., \& Afza, M. (1993). Leader power, commitment, satisfaction, compliance, and propensity to leave a job among u.s. accountants. The Journal of Social Psychology, 133(5), 611-625.

Ramakrishnaiah, D. (1998). Job satisfaction of college teachers. New Delhi, India: Discovery Publishing House.

Roberts, W. (2001). It takes more than a carrot and a stick. New York, USA: Andres McMeel.

Santhapparaj, A. S., \& Alam, S. S. (2005). Job satisfaction among academic staff in private universities in Malaysia. Journal of Social Sciences, 1(2), 72-76.

Sargent, T., \& Hannum, E. (2005). Keeping teachers happy: job satisfaction among primary school teachers in rural northwest China. Comparative Education Review, 49(2), 173-204.

Schneider, M. (2003). Linking school facility conditions to teacher satisfaction and success. Washington, USA: National Clearinghouse for Educational Facilities.

Scott, C., \& Dinham, S. (2003). The development of scales to measure teacher and school executive occupational satisfaction. Journal of Educational Administration, 41(1), 74-86.

Seseer, B. (2007). Perceived presidential leadership styles and faculty job satisfaction at Mongolian public universities. (Doctoral Thesis, Purdue University, Indiana, USA). Retrieved from http://docs.lib.purdue.edu/dissertations/AAI3291131/

Shah, S. (2009). The impact of societal culture on practice: people management in colleges in Pakistan. Journal of Educational Leadership, Policy and Practice, 24(2) 3-17.

Shann, M. H. (1998). Professional commitment and satisfaction among teachers in urban middle schools. The Journal of Educational Research, 92(2), 67-73.

Sharma, R. D., \& Jyoti, J. (2009). Job satisfaction of university teachers: an empirical study'. journal of services research, $9(2), 51-80$. 
Stumpf, M. N. (2003). The relationship of perceived leadership styles of North Carolina county extension directors' to job satisfaction of county extension professionals (Doctoral dissertation). Retrieved from https://repository.lib.ncsu.edu/handle/1840.16/5913

Tasnim, S. (2006). Job satisfaction among female teachers: a study on primary schools in Bangladesh (Master's thesis, Bergen, Norway). Retrieved from bora.uib.no/bitstream/1956/1474/1/Masteroppgavetasnim.pdf

Taylor, D. L., \& Tashakkori, A. (1995). Decision participation and school climate as predictors of job satisfaction and teacher's sense of efficacy. Journal of Experimental Education, 63(3), 217-227.

Toker, B. (2011). Job satisfaction of academic staff: an empirical study on Turkey. Quality Assurance in Education, 19(2), 156-169.

Worrell, T. G. (2004). School psychologists' job satisfaction: ten years later (Doctoral dissertation). Retrieved from https://vtechworks.lib.vt.edu/handle/10919/37424

Zembylas, M., \& Papanastasiou, E. (2004). Job satisfaction among school teachers in Cyprus. Journal of Educational Administration, 42(3), 357-374.

Zembylas, M., \& Papanastasiou, E. (2006). Teacher job satisfaction in Cyprus: the results of a mixedmethods approach. Paper presented at the Educational Administration and Management conference, Nicosia, Cyprus. Retrieved from https://www.researchgate.net/.../266870335

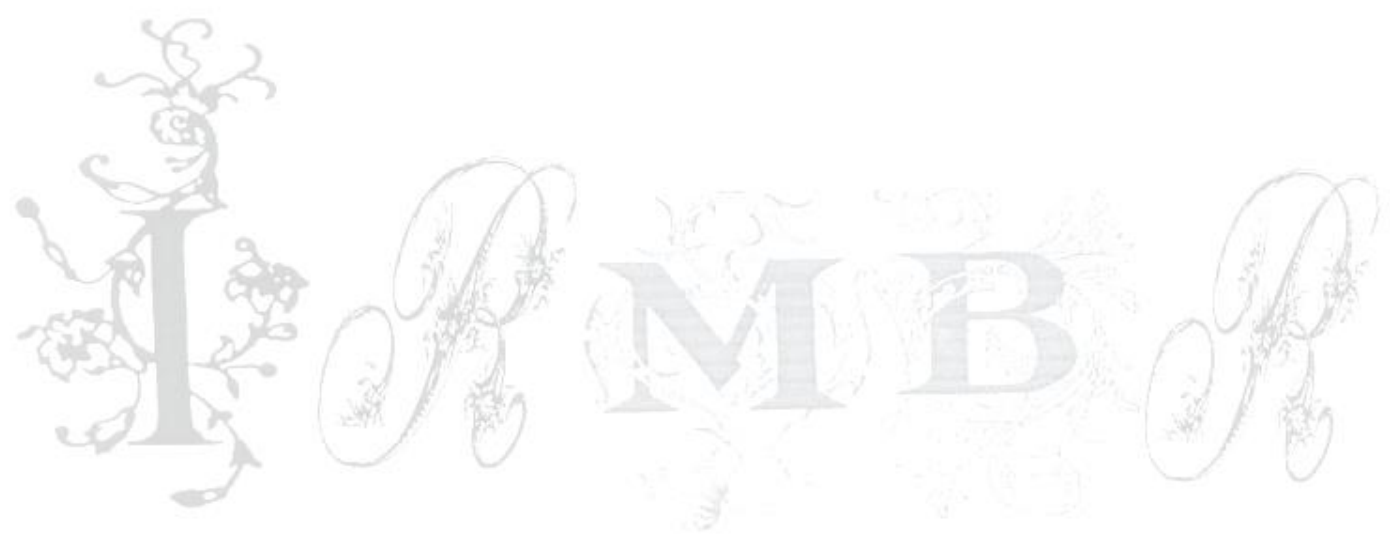

